\title{
ZnO-Nanorod Dye-Sensitized Solar Cells: New Structure without a Transparent Conducting Oxide Layer
}

\author{
Ming-Hong Lai, ${ }^{1}$ Auttasit Tubtimtae, ${ }^{1}$ Ming-Way Lee, ${ }^{1}$ and Gou-Jen Wang ${ }^{2}$ \\ ${ }^{1}$ Department of Physics, Institute of Nanoscience, National Chung Hsing University, Taichung 402, Taiwan \\ ${ }^{2}$ Department of Mechanical Engineering, National Chung Hsing University, Taichung 402, Taiwan
}

Correspondence should be addressed to Ming-Way Lee, mwl@phys.nchu.edu.tw

Received 24 November 2009; Accepted 21 December 2009

Academic Editor: Gaetano Di Marco

Copyright ( 92010 Ming-Hong Lai et al. This is an open access article distributed under the Creative Commons Attribution License, which permits unrestricted use, distribution, and reproduction in any medium, provided the original work is properly cited.

\begin{abstract}
Conventional nanorod-based dye-sensitized solar cells (DSSCs) are fabricated by growing nanorods on top of a transparent conducting oxide (TCO, typically fluorine-doped tin oxide-FTO). The heterogeneous interface between the nanorod and TCO forms a source for carrier scattering. This work reports on a new DSSC architecture without a TCO layer. The TCO-less structure consists of $\mathrm{ZnO}$ nanorods grown on top of a $\mathrm{ZnO}$ film. The $\mathrm{ZnO}$ film replaced FTO as the TCO layer and the $\mathrm{ZnO}$ nanorods served as the photoanode. The $\mathrm{ZnO}$ nanorod/film structure was grown by two methods: (1) one-step chemical vapor deposition (CVD) (2) two-step chemical bath deposition (CBD). The thicknesses of the nanorods/film grown by CVD is more uniform than that by CBD. We demonstrate that the TCO-less DSSC structure can operate properly as solar cells. The new DSSCs yield the best shortcurrent density of $3.96 \mathrm{~mA} / \mathrm{cm}^{2}$ and a power conversion efficiency of $0.73 \%$ under $85 \mathrm{~mW} / \mathrm{cm}^{2}$ of simulated solar illumination. The open-circuit voltage of $0.80 \mathrm{~V}$ is markedly higher than that from conventional ZnO DSSCs.
\end{abstract}

\section{Introduction}

Dye-sensitized solar cells (DSSC) are a promising lowcost, green energy source $[1,2]$. A power conversion efficiency of $11.18 \%$ has been achieved in 2005 [3]. The high efficiency of DSSCs can be attributed to the structure of a photoelectrode which consists of a layer of nanoparticle $\mathrm{TiO}_{2}$ sintered to a transparent-conducting oxide (TCO). The mesoporous $\mathrm{TiO}_{2}$ nanoparticles increase the surface area for dye chemisorptions to a thousand folds over that of a flat electrode of the same size [4]. The progress in enhancing the performance of DSSCs has been slow over the last decade. One of the main problems is the limited diffusion length of the photogenerated electrons. The photogenerated carriers conduct via random hopping through a percolated path in a three-dimensional network of $\mathrm{TiO}_{2}$ nanoparticles. Previous studies have shown that the photogenerated carriers must undergo $10^{3}-10^{6}$ hoppings (trapping and detrapping) before they reach the collecting electrodes [5]. Carrier trapping, presumably by defect states at the surface of $\mathrm{TiO}_{2}$ nanoparticles $[6,7]$, leads to a low electron diffusion coefficient $\left(7 \times 10^{-6} \mathrm{~cm}^{2} \mathrm{~V}^{-1} \mathrm{~s}^{-1}\right)[8]$, which is several orders of magnitude smaller than that of single-crystal $\mathrm{TiO}_{2}$ [9].

To improve the electron transport, researchers have tried to design DSSCs without a nanoparticulate structure. One promising approach is to replace the $\mathrm{TiO}_{2}$ nanoparticles with crystalline $\mathrm{TiO}_{2}$ nanorods (or nanowires, nanotubes), thereby eliminating the grain boundaries between nanoparticles. $\mathrm{TiO}_{2}$-nanorod DSSCs have yielded recombination time constants an order of magnitude longer and significantly higher charge-collection efficiencies than that of nanoparticulate DSSCs [10, 11].

Work on nanorod-based DSSCs has been based on the $\mathrm{TiO}_{2}$ system $[12,13]$, although recently the $\mathrm{ZnO}$ system has also started to attract more attention [14, 15]. $\mathrm{ZnO}$ has an energy gap of $3.37 \mathrm{eV}$, nearly identical to that of $\mathrm{TiO}_{2}$. Currently, $\mathrm{ZnO}$ nanorod arrays are grown on a TCO glass (fluorine-doped tin oxide-FTO). A disadvantage in this structure is that a heterogeneous interface exists between the FTO glass and the nanorods, which forms a source for electron scattering. 


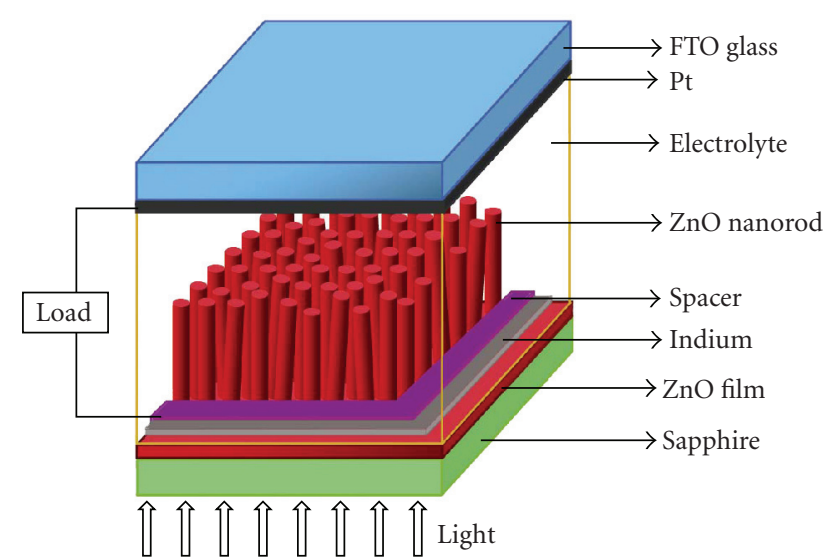

FIGURE 1: Schematic structure of the $\mathrm{ZnO}$-nanorod dye-sensitized solar cell.

To increase the conversion efficiency of nanorod-based DSSCs, it would be desirable to eliminate the interface between FTO and the $\mathrm{ZnO}$ nanorods. Replacing the FTO layer with a $\mathrm{ZnO}$ film could eliminate the heterogeneous interface. Further more, since $\mathrm{ZnO}$ is transparent to the whole visible spectrum, it is a good TCO material. Chen et al. have recently carried out this concept by growing $\mathrm{ZnO}$ nanorods on a $\mathrm{ZnO}$ film using a two-step method [16]. In this work we grew $\mathrm{ZnO}$ nanorods on a $\mathrm{ZnO}$ film using two different techniques: one-step chemical vapor deposition (CVD) and two-step chemical bath deposition (CBD). The photovoltaic properties of the TCO-less DSSC samples were systematically investigated. The results were compared to those of a conventional $\mathrm{ZnO}$-nanorod DSSC (i.e., $\mathrm{ZnO}$ nanorods grown on an FTO film). The electron transport characteristics were analyzed using the one-diode circuit model.

\section{Experimental Procedure}

\subsection{Sample Growth}

2.1.1. CVD Growth. In the first experiment we grew $\mathrm{ZnO}$ nanorods on a $\mathrm{ZnO}$ film using the one-step CVD technique. High-purity $\mathrm{Zn}$ slugs $(6 \mathrm{~N})$ were placed on an alumina boat inside a quartz one-inch diameter tube in a furnace. The c-plane (0001) sapphire single-crystalline substrates were placed $7 \mathrm{~cm}$ downstream from the $\mathrm{Zn}$ source. The growth conditions were: temperature $850-900^{\circ} \mathrm{C}$ and gas flow rates: $2 \mathrm{sccm}\left(\mathrm{O}_{2}\right)$ and $15 \mathrm{sccm}(\mathrm{Ar})$, and growth time: $35 \mathrm{~min}$. In the first stage of the growth process, a $\mathrm{ZnO}$ film grew on the sapphire substrate; in the second stage, $\mathrm{ZnO}$ nanorods started to grow on top of the $\mathrm{ZnO}$ film. The grown samples were examined by a scanning electron microscope (SEM). Photoluminescence (PL) spectra were measured using an $\mathrm{HeCd}$ laser of $325 \mathrm{~nm}$ wavelength.

2.1.2. CBD Growth. The second sample growth experiment employed a two-step CBD method. In the first step, a $\mathrm{ZnO}$ film was grown on a glass substrate; in the second step, $\mathrm{ZnO}$

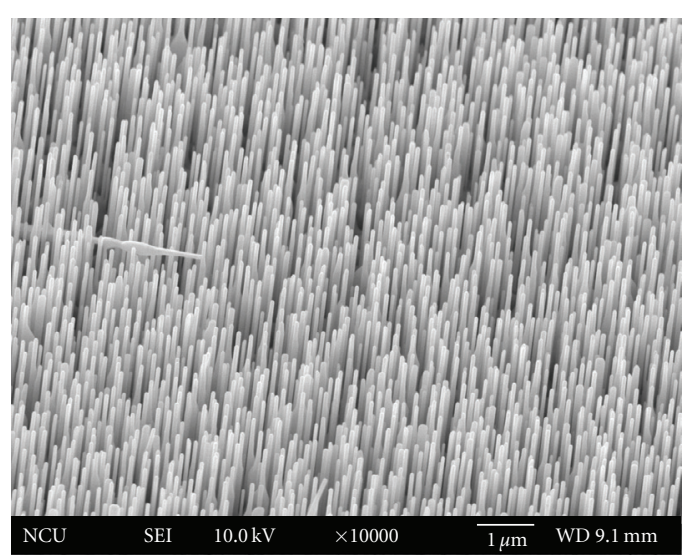

(a)

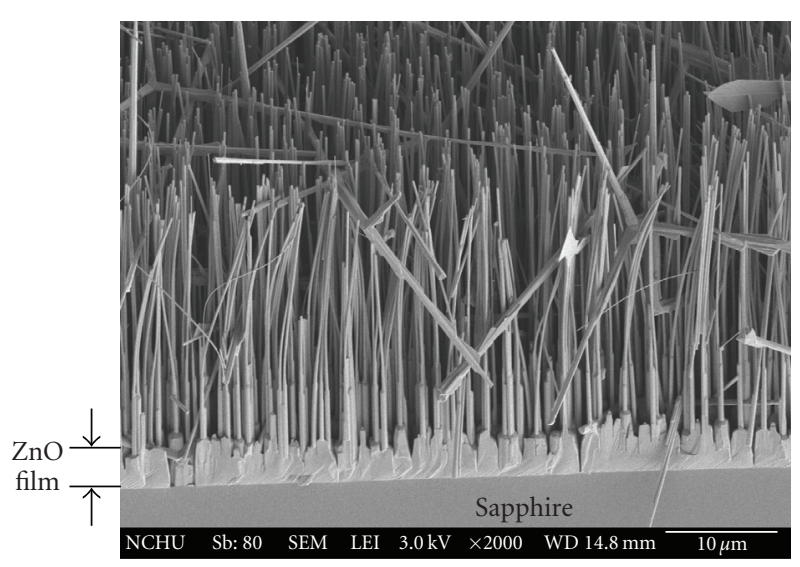

(b)

FIgURE 2: SEM images: (a) top view, (b) cross-sectional view, of $\mathrm{ZnO}$ nanorods on top of a $\mathrm{ZnO}$ film grown by the one-step CVD method.

nanorod arrays were synthesized on top of the $\mathrm{ZnO}$ film. The substrates were Corning 1737 glass. Aqueous solutions of $0.08 \mathrm{M}$ of zinc nitrate hexahydrate $\mathrm{Zn}\left(\mathrm{NO}_{3}\right)_{2} \cdot 6 \mathrm{H}_{2} \mathrm{O}$ and $0.05 \mathrm{M}$ of hexamethylenetetramine $\mathrm{C}_{6} \mathrm{H}_{12} \mathrm{~N}_{4}$ (HMT) were used as the precursors for the $\mathrm{ZnO}$ films. One $\mathrm{M}$ of hydrogen peroxide $\left(\mathrm{H}_{2} \mathrm{O}_{2}\right)$ was added to the solution to make it more turbid ( $\mathrm{pH} \sim 6.0-6.5$ ), which is advantageous for obtaining more uniform thin films. A layer of $\mathrm{ZnO}$ film was deposited on the substrate after the reaction at $90^{\circ} \mathrm{C}$ for $1.3 \mathrm{~h}$. For the growth of $\mathrm{ZnO}$ nanorods, the $\mathrm{ZnO}$ film-coated substrate was immersed vertically in a beaker containing a $0.01 \mathrm{M}$ solution of the precursors used in the first step (zinc nitrate hexahydrate and $\mathrm{HMT}$ ). The reaction was carried out at $95^{\circ} \mathrm{C}$ for $5 \mathrm{~h}$. The process was repeated five-to-six times in order to obtain higher density and longer nanorods.

2.1.3. Growth of ZnO Nanorods for Conventional DSSCs. For comparison, a third reference sample was grown by the CBD method. The sample had the structure of conventional DSSCs- ZnO nanorods grown on an FTO glass substrate. Prior to the growth, a seed layer of $\mathrm{ZnO}$ nanoparticles was first deposited by immersing an FTO substrate into 


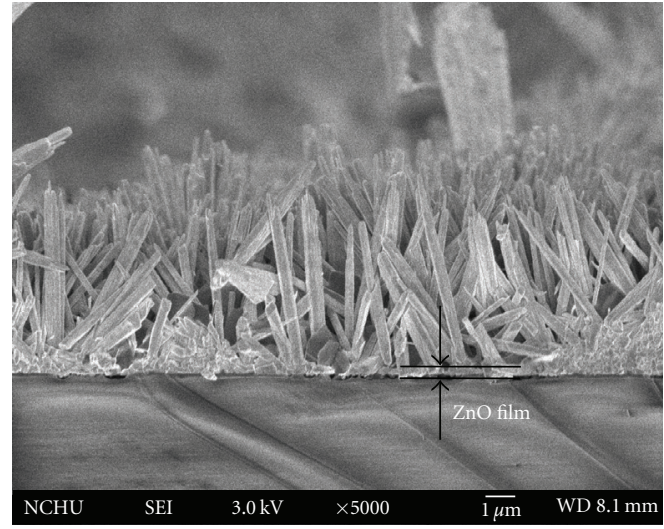

FIGURE 3: SEM image of $\mathrm{ZnO}$ nanorods on top of a $\mathrm{ZnO}$ film grown by the two-step CBD method.

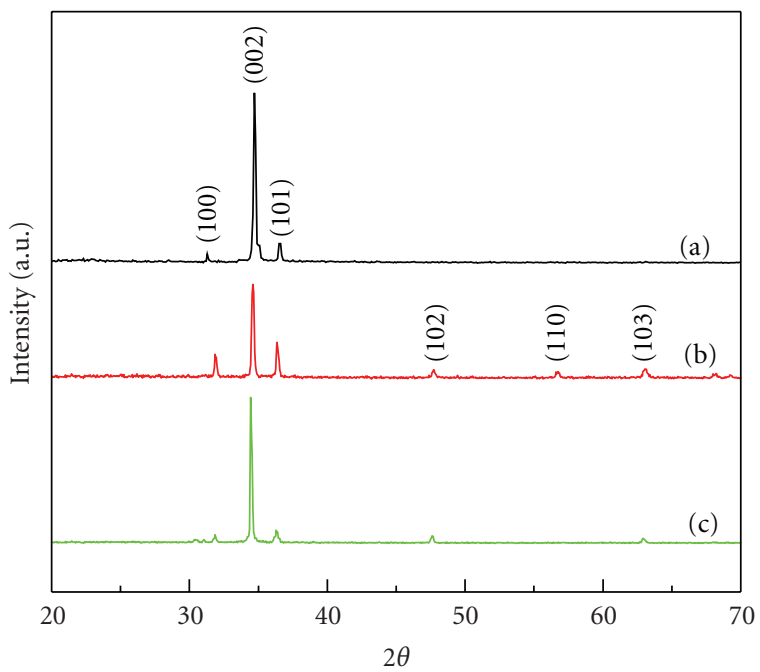

Figure 4: X-ray diffraction patterns of the $\mathrm{ZnO}$ nanorod/film samples. curve (a): CVD grown, curve (b): CBD grown, and curve (c): conventional.

a solution of $0.5 \mathrm{M}$ zinc acetate $\mathrm{Zn}\left(\mathrm{CH}_{3} \mathrm{COO}\right)_{2} \cdot 2 \mathrm{H}_{2} \mathrm{O}$ and HMT for $30 \mathrm{~min}$. $\mathrm{ZnO}$ nanorods were then grown on the substrate using the CBD method. The growth conditions were identical to those in Section 2.1.2.

2.2. Fabrication of Solar Cells. The TCO-less ZnO DSSCs were fabricated as follows. The $\mathrm{ZnO}$ film/nanorod sample was sensitized by immersion in a solution of $2 \times 10^{-4} \mathrm{M}$ N719 dye for $24 \mathrm{~h}$ at room temperature. An FTO glass with Pt foil $150 \mu \mathrm{m}$ in thickness served as the counter electrode. The $\mathrm{ZnO}$ electrode and the counter electrode were assembled and sealed by a $25 \mu \mathrm{m}$ thick parafilm spacer. The electrolyte was composed of $0.5 \mathrm{M} \mathrm{LiI}, 0.05 \mathrm{M} \mathrm{I}_{2}, 0.5 \mathrm{M}$ 4-tert-butylpyridine, and $0.6 \mathrm{M}$ 1-butyl-methylimidazoilium iodide in acetonitrile and valeronitrile. Figure 1 shows the schematic structure of a fabricated TCO-less DSSC on the grown $\mathrm{ZnO}$ film/ nanorods.

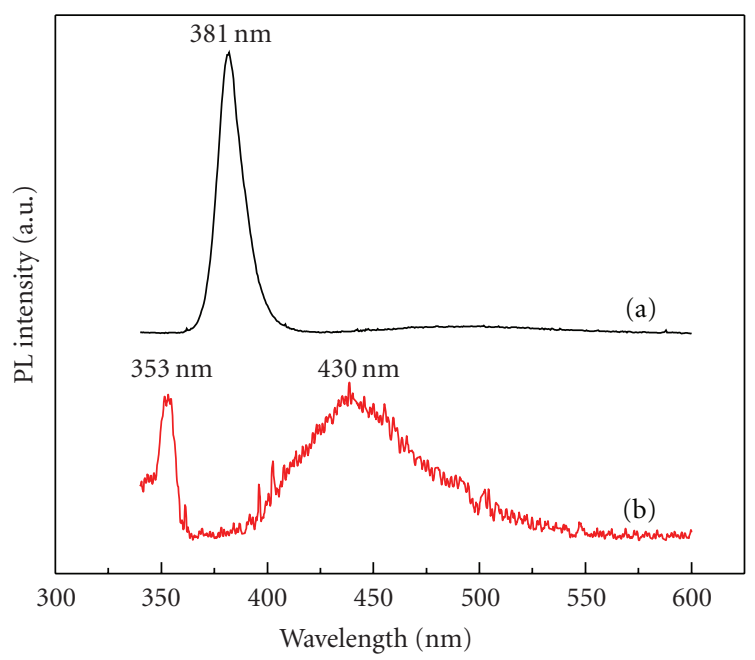

FIGURE 5: Room-temperature photoluminescence spectra of $\mathrm{ZnO}$ nanorods. Curve (a): CVD grown sample, curve (b): CBD grown sample.

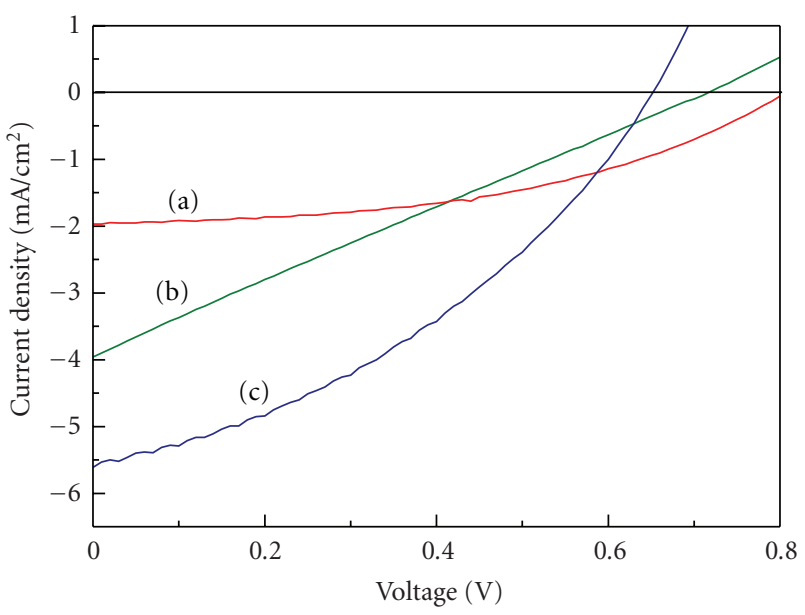

Figure 6: $I-V$ characteristics of $\mathrm{ZnO}$ nanorod DSSCs. Curve (a): CVD-grown sample, curve (b): CBD-grown sample, and curve (c): conventional sample.

2.3. Photovoltaic Measurements. The current-voltage (I$V)$ characteristics measurements were performed using a $150 \mathrm{~W}$ Xe lamp (Oriel). A filter was placed in front of the sample to simulate the AM 1.5 spectrum. The active area of the cell was $0.3 \mathrm{~cm} \times 0.3 \mathrm{~cm}$. The photocurrent was recorded using a Keithley 2400 sourcemeter. The conversion efficiency is calculated as follows: $\eta=J_{\mathrm{sc}} \cdot V_{\mathrm{oc}} \cdot \mathrm{FF} / I_{\mathrm{ph}}$, where $J_{\mathrm{sc}}$ $\left(\mathrm{mA} / \mathrm{cm}^{2}\right)$ is the short-circuit current density, $V_{\mathrm{oc}}$ is the open-circuit voltage, FF is the fill factor, and $I_{\mathrm{ph}}\left(\mathrm{mA} / \mathrm{cm}^{2}\right)$ is the intensity of the incident light.

\section{Results and Discussion}

3.1. Structure Characterization. Figure 2 shows (a) top view, (b) cross-sectional SEM images of $\mathrm{ZnO}$ nanorods on a $\mathrm{ZnO}$ film grown by the one-step CVD method. The nanorods 


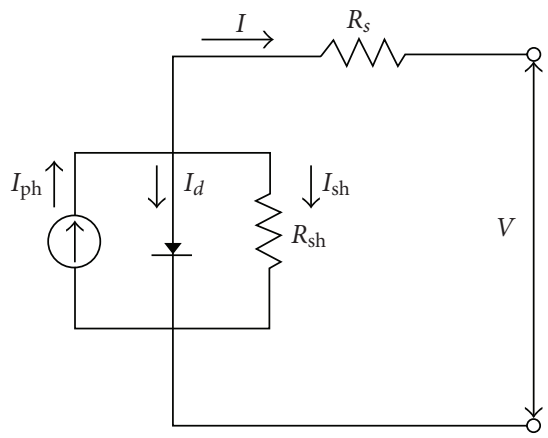

FIgURE 7: Equivalent circuit of the one-diode model.

TABLe 1: Photovoltaic characteristics of three $\mathrm{ZnO}$-nanorod dyesensitized solar cells grown by the one-step CVD, two-step CBD and conventional methods. The incident light intensity is $85 \mathrm{~mW} / \mathrm{cm}^{2}$.

\begin{tabular}{lcccc}
\hline Sample & $V_{\text {oc }}(\mathrm{V})$ & $J_{\text {sc }}\left(\mathrm{mA} / \mathrm{cm}^{2}\right)$ & FF $(\%)$ & $\eta(\%)$ \\
\hline CVD & 0.80 & 1.97 & 39.4 & 0.73 \\
CBD & 0.72 & 3.96 & 20.0 & 0.66 \\
conventional & 0.65 & 5.51 & 38.2 & 1.37 \\
\hline
\end{tabular}

have an average length of $\sim 20 \mu \mathrm{m}$, diameter ranging from 100 to $200 \mathrm{~nm}$ and they are mostly vertically aligned with the substrate. A $\mathrm{ZnO}$ film of thickness $\sim 2 \mu \mathrm{m}$ can be clearly seen. Figure 3 shows a SEM image of $\mathrm{ZnO}$ nanorods grown by the two-step CBD method. The nanorods have diameters ranging from 50 to $500 \mathrm{~nm}$ and length from 7 to $10 \mu \mathrm{m}$. The $\mathrm{ZnO}$ film has a thickness ranging from 0.3 to $1 \mu \mathrm{m}$. It can be seen that the CVD-grown nanorods have a more uniform distribution in thickness than that in the CBD sample. The thickness of the CVD-grown $\mathrm{ZnO}$ film is also more uniform.

Figure 4 shows the $\mathrm{X}$-ray diffraction patterns of the $\mathrm{ZnO}$ film/nanorods grown by the three methods. The diffraction patterns correspond to the hexagonal wurtzite structure with lattice constants of $a=3.176 \AA, c=5.187 \AA$. In the CVD sample, the most pronounced peak is (002), indicating that the preferential growth is along the $c$ axis of a nanorod. In contrast, the diffraction pattern of the conventional $\mathrm{ZnO}$ sample shows the main (002) peak along with many weak peaks, indicating no preferential orientation in the nanorod growth. The difference in nanorod orientation is an effect of the substrate. In the CVD growth, single-crystalline sapphire was used, resulting in oriented nanorods. In the conventional method, FTO glass without preferential orientations was used, resulting in randomly orientated nanorods.

Figure 5 shows the room-temperature PL spectra of $\mathrm{ZnO}$ nanorods grown by the CVD and CBD methods. The CVD sample shows a sharp blue peak at $\lambda=380 \mathrm{~nm}$, attributed to the free exciton emission of $\mathrm{ZnO}$. In the CBD sample this blue peak is upshifted to $353 \mathrm{~nm}$ and a broad peak at $430 \mathrm{~nm}$ is observed. The latter peak can be attributed to singly ionized oxygen vacancies [17]. We observed that CVD processing in a lower oxygen partial pressure led to more oxygen vacancies and a larger $430 \mathrm{~nm}$ peak.
3.2. Photovoltaic Properties. Figure 6 shows the photocurrentvoltage $(I-V)$ characteristics for three $\mathrm{ZnO}$-nanorod DSSC samples grown by the CVD, CBD and conventional methods. The photovoltaic characteristics are listed in Table 1. The CVD-grown sample has an open circuit voltage $V_{\text {oc }}$ of $0.80 \mathrm{~V}$ and an energy conversion efficiency $\eta=0.73 \%$. The CBD sample has a higher short-circuit current density of $J_{\mathrm{sc}}=3.96 \mathrm{~mA} / \mathrm{cm}^{2}$. The efficiency is very close to that of Chen et al. $(0.77 \%)$ for a DSSC with the same TCO-less structure. The conventional DSSC has a conversion efficiency of $\eta=1.37 \%$. In general, the energy conversion efficiency of $\mathrm{ZnO}$ DSSCs is lower than that of $\mathrm{TiO}_{2}$ DSSCs. Note that the efficiency of ZnO-nanorod-based DSSCs is typically $1 \%-2 \%$ [18].

A notable feature of the present result is that the opencircuit voltage $V_{\text {oc }}$ of the TCO-less DSSCs is relatively high $(0.80 \mathrm{~V})$, about $20 \%-40 \%$ higher than that of conventional ZnO-nanorod DSSCs, typically $\sim 0.6 \mathrm{~V}[19,20]$. According to the kinetic model, the open-circuit voltage is limited by $E_{F}-E_{\text {redox }}$, where $E_{F}$ is the Fermi level of $\mathrm{ZnO}$ and $E_{\text {redox }}$ is the redox potential of the electrolyte. The actual $V_{\mathrm{oc}}$ obtained in experiments is lower than the theoretical upper limit due to the dark current in the solar cell. The dark current is mainly caused by carrier recombination between the photoinjected electrons in the semiconductor and the positively charged dye molecules or electrolyte. Our present result suggests that carrier recombination in the TCO-less structure is reduced, resulting in a larger $V_{\text {occ }}$.

The conversion efficiencies of the TCO-less DSSCs are lower than those of the conventional DSSC. We attribute this to the large resistance in the $\mathrm{ZnO}$ film. We analyze the series resistance $R_{\mathrm{S}}$ and shunt resistance $R_{\mathrm{sh}}$ of the DSSC from $I-V$ curve using the one-diode model. The equivalent circuit is shown in Figure 7. The equation of the circuit is

$$
\begin{aligned}
I & =I_{\mathrm{ph}}-I_{\mathrm{d}}-I_{\mathrm{sh}} \\
& =I_{\mathrm{ph}}-I_{0}\left\{\exp \left(q \frac{V+I R_{\mathrm{s}}}{n k T}\right)-1\right\}-\frac{V+I R_{\mathrm{s}}}{R_{\mathrm{sh}}},
\end{aligned}
$$

where $I_{\mathrm{ph}}$ is the photo current, $I_{\mathrm{d}}$ is the diode current, $I_{\mathrm{sh}}$ is the shunt current, $I_{0}$ is the initial current, $n$ is the diode factor, $q$ the electric charge, and $k$ is the Boltzmann constant. The $I-V$ curve (a) in Figure 6 (the CVD sample) was taken for fitting. The best fit yields the parameters: $J_{\mathrm{ph}}=$ $2.07 \mathrm{~mA} / \mathrm{cm}^{2}, J_{0}=0.37 \mathrm{nA} / \mathrm{cm}^{2}, R_{\mathrm{s}}=1850 \Omega$, and $R_{\mathrm{sh}}=$ $25 \mathrm{k} \Omega$. Considering recombination current in DSSCs, the diode factor $n$ was set to 2 in the fitting. The series resistance $R_{\mathrm{S}}$ is relatively large for solar cells, which is because the $\mathrm{ZnO}$ film is undoped and, therefore, has a large resistance. Doping to the film with $\mathrm{Ga}$ or In should produce a lower-resistance film, which will increase the efficiency of the DSSCs.

The one-step growth method in the present work has several advantages over Chen's two-step MOCVD method. In Chen's method, a Ga-doped $\mathrm{ZnO}$ film was grown on the substrate in the first step; $\mathrm{ZnO}$ nanotips were grown on top of the $\mathrm{ZnO}$ film in the second step. The experimental conditions had to be varied during the two steps. In the present work, a one-step vapor-transport CVD method was used to grow the $\mathrm{ZnO}$ film/nanorod structure. The sample growth could be 
completed in one run. The new method is simpler, reaction time is shorter, and the growth equipment is much cheaper than MOCVD.

\section{Conclusion}

In conclusion, we have demonstrated a new DSSC structure without a TCO layer. A $\mathrm{ZnO}$ film, grown by the onestep CVD or the two-step CBD method, is used to replace the TCO layer. The new structure eliminates the interface between the nanorod and the TCO film. The $\mathrm{ZnO}$ nanorods and $\mathrm{ZnO}$ films grown by the CVD method have more uniform thickness. The DSSC structure yields an opencircuit voltage markedly higher than that from DSSC on an FTO glass. Higher electrical conductance in the $\mathrm{ZnO}$ film is needed to improve the DSSC efficiency.

\section{References}

[1] B. O’Regan and M. Grätzel, "A low-cost, high-efficiency solar cell based on dye-sensitized colloidal $\mathrm{TiO}_{2}$ films," Nature, vol. 353, no. 6346, pp. 737-740, 1991.

[2] M. Grätzel, "Perspectives for dye-sensitized nanocrystalline solar cells," Progress in Photovoltaics, vol. 8, no. 1, pp. 171-185, 2000.

[3] M. K. Nazeeruddin, F. de Angelis, S. Fantacci, et al., "Combined experimental and DFT-TDDFT computational study of photoelectrochemical cell ruthenium sensitizers," Journal of the American Chemical Society, vol. 127, no. 48, pp. 1683516847, 2005.

[4] K. Kalyanasundaram, N. Vlachopoulos, V. Krishnan, A. Monnier, and M. Grätzel, "Sensitization of $\mathrm{TiO}_{2}$ in the visible light region using zinc porphyrins," Journal of Physical Chemistry, vol. 91, no. 9, pp. 2342-2347, 1987.

[5] K. D. Benkstein, N. Kopidakis, J. van de Lagemaat, and A. J. Frank, "Influence of the percolation network geometry on electron transport in dye-sensitized titanium dioxide solar cells," Journal of Physical Chemistry B, vol. 107, no. 31, pp. 7759-7767, 2003.

[6] A. C. Fisher, L. M. Peter, E. A. Ponomarev, A. B. Walker, and K. G. U. Wijayantha, "Intensity dependence of the back reaction and transport of electrons in dye-sensitized nanocrystalline $\mathrm{TiO}_{2}$ solar cells," Journal of Physical Chemistry B, vol. 104, no. 5, pp. 949-958, 2000.

[7] J. van de Lagemaat and A. J. Frank, "Nonthermalized electron transport in dye-sensitized nanocrystalline $\mathrm{TiO}_{2}$ films: transient photocurrent and random-walk modeling studies," Journal of Physical Chemistry B, vol. 105, no. 45, pp. 1119411205, 2001.

[8] Th. Dittrich, E. A. Lebedev, and J. Weidmann, "Electron drift mobility in porous $\mathrm{TiO}_{2}$ (anatase)," Physica Status Solidi A, vol. 165, no. 2, pp. R5-R6, 1998.

[9] L. Forro, O. Chauvet, D. Emin, L. Zuppiroli, H. Berger, and F. Lévy, "High mobility n-type charge carriers in large single crystals of anatase $\left(\mathrm{TiO}_{2}\right)$," Journal of Applied Physics, vol. 75, no. 1, pp. 633-635, 1994.

[10] G. K. Mor, K. Shankar, M. Paulose, O. K. Varghese, and C. A. Grimes, "Use of highly-ordered $\mathrm{TiO}_{2}$ nanotube arrays in dyesensitized solar cells," Nano Letters, vol. 6, no. 2, pp. 215-218, 2006.
[11] K. Zhu, N. R. Neale, A. Miedaner, and A. J. Frank, "Enhanced charge-collection efficiencies and light scattering in dyesensitized solar cells using oriented $\mathrm{TiO}_{2}$ nanotubes arrays," Nano Letters, vol. 7, no. 1, pp. 69-74, 2007.

[12] M. Adachi, Y. Murata, I. Okada, and S. Yoshikawa, "Formation of titania nanotubes and applications for dye-sensitized solar cells," Journal of the Electrochemical Society, vol. 150, no. 8, pp. G488-G493, 2003.

[13] M. Dürr, A. Schmid, M. Obermaier, S. Rosselli, A. Yasuda, and G. Nelles, "Low-temperature fabrication of dye-sensitized solar cells by transfer of composite porous layers," Nature Materials, vol. 4, no. 8, pp. 607-611, 2005.

[14] M. Guo, P. Diao, X. Wang, and S. Cai, "The effect of hydrothermal growth temperature on preparation and photoelectrochemical performance of $\mathrm{ZnO}$ nanorod array films," Journal of Solid State Chemistry, vol. 178, no. 10, pp. 32103215, 2005.

[15] J. B. Baxter and E. S. Aydil, "Nanowire-based dye-sensitized solar cells," Applied Physics Letters, vol. 86, no. 5, Article ID 045004, pp. 1-3, 2005.

[16] H. Chen, A. Du Pasquier, G. Saraf, J. Zhong, and Y. Lu, "Dyesensitized solar cells using $\mathrm{ZnO}$ nanotips and $\mathrm{Ga}$-doped $\mathrm{ZnO}$ films," Semiconductor Science and Technology, vol. 23, no. 4, Article ID 045004, 2008.

[17] K. Vanheusden, W. L. Warren, C. H. Seager, D. R. Tallant, J. A. Voigt, and B. E. Gnade, "Mechanisms behind green photoluminescence in $\mathrm{ZnO}$ phosphor powders," Journal of Applied Physics, vol. 79, no. 10, pp. 7983-7990, 1996.

[18] C. Y. Jiang, X. W. Sun, G. Q. Lo, D. L. Kwong, and J. X. Wang, "Improved dye-sensitized solar cells with a $\mathrm{ZnO}$-nanoflower photoanode," Applied Physics Letters, vol. 90, no. 26, Article ID 263501, 2007.

[19] J.-J. Wu, G.-R. Chen, H.-H. Yang, C.-H. Ku, and J.-Y. Lai, "Effects of dye adsorption on the electron transport properties in ZnO-nanowire dye-sensitized solar cells," Applied Physics Letters, vol. 90, no. 21, Article ID 213109, 2007.

[20] I.-D. Kim, J.-M. Hong, B. H. Lee, et al., "Dye-sensitized solar cells using network structure of electrospun $\mathrm{ZnO}$ nanofiber mats," Applied Physics Letters, vol. 91, no. 16, Article ID 163109, 2007. 


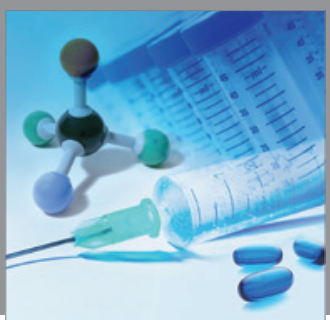

International Journal of

Medicinal Chemistry

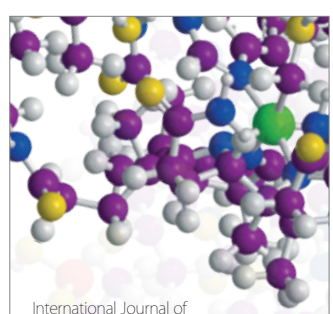

Carbohydrate Chemistry

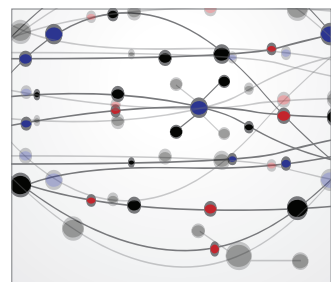

The Scientific World Journal
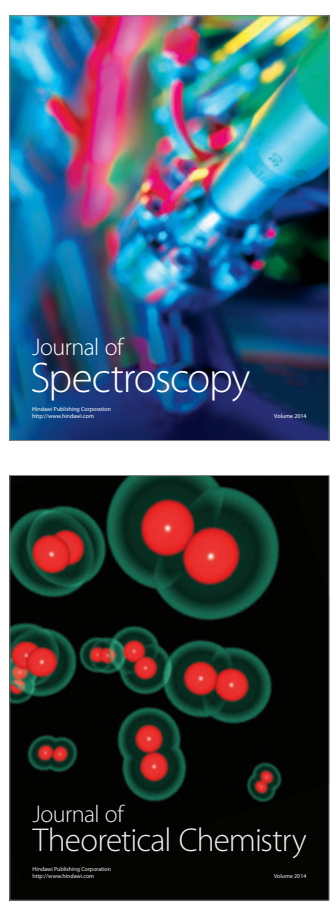
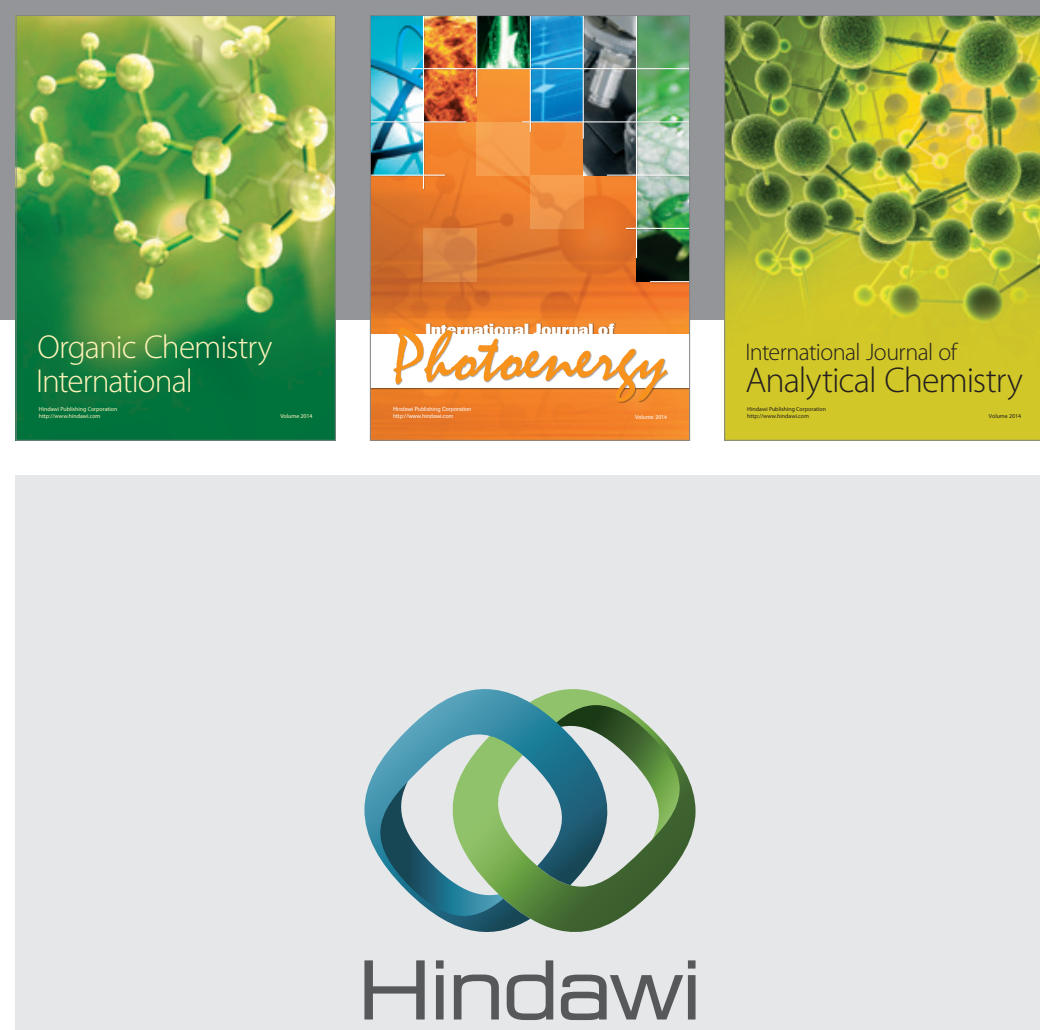

Submit your manuscripts at

http://www.hindawi.com
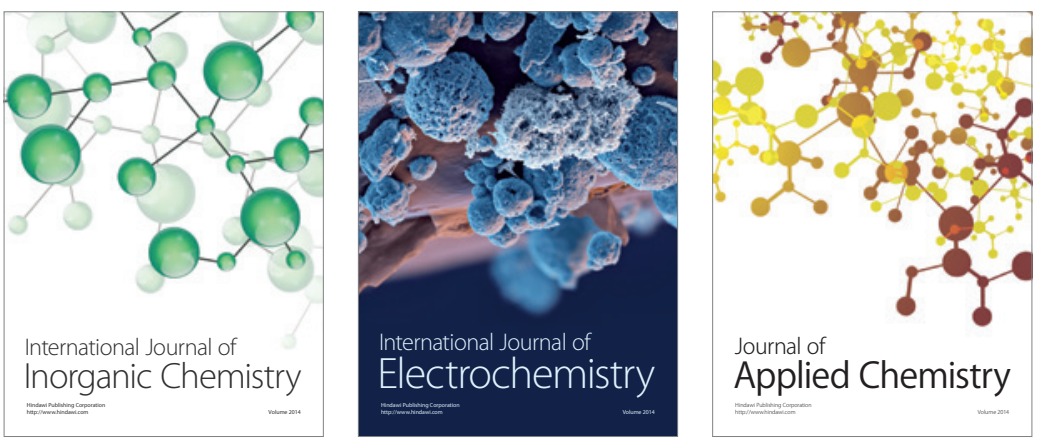

Journal of

Applied Chemistry
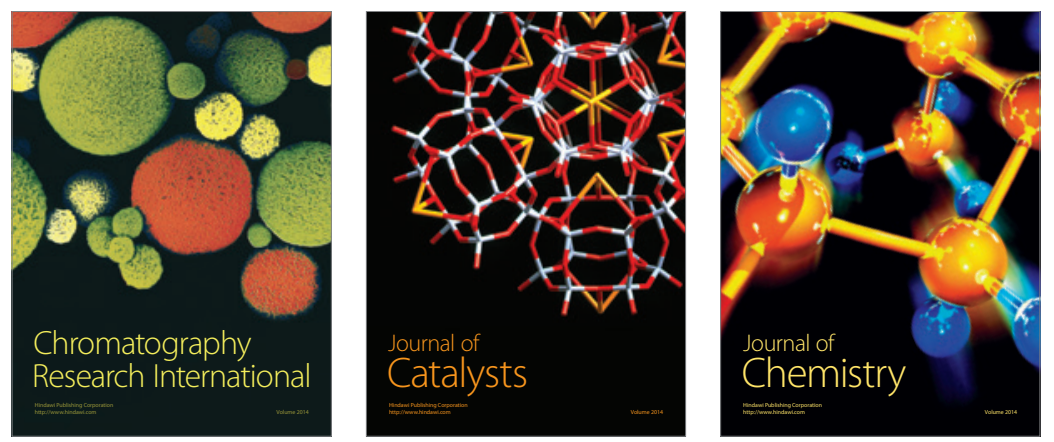
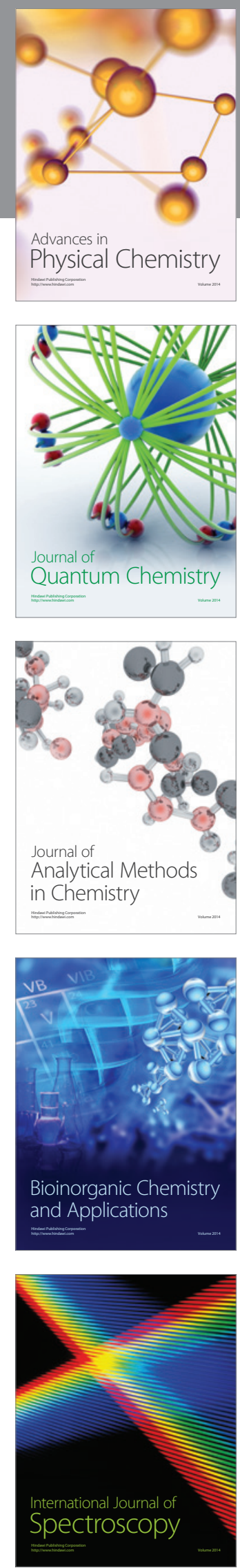